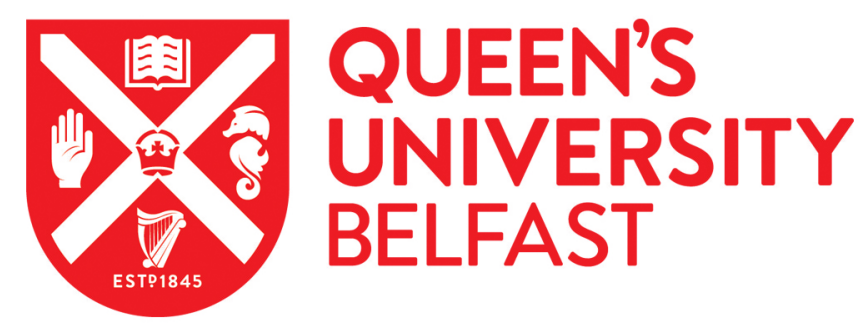

\title{
HPV prevalence and type-distribution in cervical cancer and premalignant lesions of the cervix: A population-based study from Northern Ireland
}

Anderson, L. A., O'Rorke, M. A., Jamison, J., Wilson, R., \& Gavin, A. T. (2016). HPV prevalence and typedistribution in cervical cancer and premalignant lesions of the cervix: A population-based study from Northern Ireland. Journal of Medical Virology. https://doi.org/10.1002/jmv.24447

Published in:

Journal of Medical Virology

Document Version:

Peer reviewed version

Queen's University Belfast - Research Portal:

Link to publication record in Queen's University Belfast Research Portal

\begin{abstract}
Publisher rights
(C) 2016 Wiley Periodicals, Inc.

This is the peer reviewed version of the following article: Anderson, L. A., O'Rorke, M. A., Wilson, R., Jamison, J., Gavin, A. T. and on behalf of the Northern Ireland HPV Working Group (2016), HPV prevalence and type-distribution in cervical cancer and premalignant lesions of the cervix: A population-based study from Northern Ireland. J. Med. Virol., which has been published in final form at

http://onlinelibrary. wiley.com/doi/10.1002/jmv.24447/abstract. This article may be used for non-commercial purposes in accordance with Wiley Terms and Conditions for Self-Archiving.

General rights

Copyright for the publications made accessible via the Queen's University Belfast Research Portal is retained by the author(s) and / or other copyright owners and it is a condition of accessing these publications that users recognise and abide by the legal requirements associated with these rights.
\end{abstract}

\section{Take down policy}

The Research Portal is Queen's institutional repository that provides access to Queen's research output. Every effort has been made to ensure that content in the Research Portal does not infringe any person's rights, or applicable UK laws. If you discover content in the Research Portal that you believe breaches copyright or violates any law, please contact openaccess@qub.ac.uk. 
1 ARTICLE TYPE: Original article

2 TITLE: HPV prevalence and type-distribution in cervical cancer and premalignant lesions of the

3 cervix: a population-based study from Northern Ireland.

4 RUNNING HEAD: HPV genotype prevalence in cervical cancer

5 AUTHORS: Anderson $\mathrm{LA}^{\mathrm{I}^{*}}, \mathrm{O}^{\prime}$ Rorke $\mathrm{MA}^{1}$, Wilson $\mathrm{R}^{2}$, Jamison $\mathrm{J}^{2} \&$ Gavin $\mathrm{AT}^{3}$ on behalf of the

$6 \quad$ Northern Ireland HPV Working Group.

7 AFFILIATIONS:

$8{ }^{1}$ Cancer Epidemiology and Health Services Research Group, Centre for Public Health, School of

9 Medicine Dentistry and Biomedical Sciences, Queen's University Belfast.

$10{ }^{2}$ Department of Cellular \& Molecular Pathology, Antrim Area Hospital, Northern Health \& Social Care

11 Trust.

$12{ }^{3}$ Northern Ireland Cancer Registry, Centre for Public Health, School of Medicine, Dentistry and 13 Biomedical Sciences, Queen's University Belfast.

\section{CORRESPONDING AUTHOR *}

15 Dr Lesley Anderson, Centre for Public Health, Queen's University Belfast, Institute of Clinical Sciences

16 Block B, Royal Victoria Hospital Site, Grosvenor Road, Belfast, BT12 6BJ

17 Tel: +44(0) 2890979833 | Email: l.anderson@qub.ac.uk

18 
Introduction: Assessment of Human papillomavirus (HPV) prevalence and genotype distribution is important for monitoring the impact of prophylactic HPV vaccination. This study aimed to demonstrate the HPV genotypes predominating in pre-malignant and cervical cancers in Northern Ireland (NI) before the vaccination campaign has effect.

Methods: Formalin fixed paraffin embedded tissue blocks from 2,303 women aged 16-93 years throughout NI were collated between April 2011 and February 2013. HPV DNA was amplified by PCR and HPV genotyping undertaken using the Roche ${ }^{\circledR}$ linear array detection kit.

Results: In total, 1,241 out of 1,830 eligible samples (68.0\%) tested positive for HPV, with the majority of these $[1,181 / 1,830(64.5 \%)]$ having high-risk (HR) HPV infection; $37.4 \%$ were positive for HPV-16 $(n=684)$ and 5.1\% for HPV-18 ( $n=93)$. HPV type-specific prevalence was $48.1 \%, 65.9 \%, 81.3 \%$, 92.2\% and 64.3\% among cervical intraepithelial neoplasias (CIN) grades I-III, squamous cell carcinomas (SCC) and adenocarcinoma (AC) cases, respectively. Most SCC cases (81.3\%) had only one HPV genotype detected and almost a third (32.0\%) of all cervical pathologies were HPV negative including $51.9 \%$ of CIN I ( $n=283), 34.1 \%$ CIN II ( $n=145), 18.7 \%$ of CIN III ( $n=146), 7.8 \%$ of SCC $(n=5)$ and $35.7 \%$ of $A C(n=5)$ cases.

Conclusions: This study provides important baseline data for monitoring the effect of HPV vaccination in $\mathrm{NI}$ and for comparison with other UK regions. The coverage of other HR-HPV genotypes apart from 16 and 18, including HPV-45, 31, 39 and 52, and the potential for cross protection, should be considered when considering future polyvalent vaccines.

Keywords: human papillomavirus, cervical cancer, cervical intraepithelial neoplasia, frequency, population-based.

50 
54 Annually 3,000 women are diagnosed with, and almost 1,000 die from cervical cancer in the United 55 Kingdom (UK), making it the $12^{\text {th }}$ most common cancer diagnosis and $17^{\text {th }}$ most common cancer death [Cancer Research UK, 2014]. Two main subtypes exist, squamous cell carcinoma (SCC) and adenocarcinoma (AC). Persistent infection with high-risk (HR) oncogenic human papillomavirus (HPV) family alpha-Papillomaviridae is a necessary, but insufficient cause, for invasive cervical cancer [IARC Working Group on the Evaluation of Carcinogenic Risks to Humans., 2012]; with HPV-16 and HPV-18, the most common oncogenic types, contributing to around $70 \%$ of all cases worldwide [WHO/ICO Information Centre on HPV and Cervical Cancer, 2010].

62 HPV is highly sexually transmissible with $80 \%$ of women expected to have a HPV infection at some point during their sexually active life [Alexander et al, 2012]. Many women are repeatedly infected, with most infections occurring in those aged under 25 years [de Sanjosé et al, 2007; Smith et al, 2008; Anderson et al, 2013]. However, despite frequent exposure to HPV, development of cervical cancer is uncommon with most HPV infections being transient and spontaneously regressing within two years with no residual abnormality [Castellsagué, 2008]. In some cases HPV infection may persist [Trottier et al, 2009], with some HPV genotypes more persistent than others [Louvanto et al, 2010]. Recent studies indicate a higher proportion of CIN II and CIN III lesions progressing to invasive cancer in HPV-16 positive lesions, often within as little as 10-20 years [Jaisamrarn et al, 2013; Vink et al, 2013; Wentzensen et al, 2013]. Many aspects of the natural history of HPV infection remain to be fully elucidated, including the probable existence of latent infections and potential reactivation.

Although HPV-16, 18, 31, 52 and 58 are cited among the top 10 most common HPV genotypes worldwide [Bruni et al, 2010], there is significant variation in the reported prevalence of HR-HPV genotypes between countries. We previously reported that the prevalence of any HPV infection in Northern Ireland (NI) women having a pap smear was $17.1 \%$, ranging from $42.5 \%$ in those aged 20 - 
7924 years to $4.2 \%$ in women aged $60-64$ years; HPV prevalence was lower in women with normal

80 cytology at $13.2 \%$ increasing in those with cervical disease [Anderson et al, 2013]. However, this

81 study was underpowered to detect the prevalence of HPV genotypes in high-grade cervical

82 abnormalities $(n=72)$.

83

84 The aim of the present study was therefore to provide an estimate of the background prevalence of 85 HPV infection and age-specific HPV type distribution, and to highlight the HPV genotypes most 86 frequently present in cervical cancer tissue and precursor lesions, before the HPV vaccination 87 programme alters the distribution of HPV infection in NI. Of note, unpublished data from the present 88 study has been recently incorporated into a pooled analysis of the HPV type-specific prevalence in 89 invasive cervical cancers in the UK [Mesher et al, 2014] where the overall prevalence of any HR-HPV 90 was found to be $95.8 \%$; data that will be valuable in future HPV vaccine monitoring and effectiveness 91 studies. More detailed data on the prevalence of all detected HPV genotypes stratified by five year 92 age-bands, inclusive of CIN I-III and cervical pathologies are reported herein. 
Prospectively derived formalin fixed paraffin embedded (FFPE) cervical tissue blocks (processed at all four pathology laboratories in NI) pertaining to routine diagnostic samples collected between April 2011 and February 2013 from all women attending for cervical screening across NI (populationbased cohort), and which were determined to have cervical abnormalities, were eligible for

111 inclusion. No age or histological restrictions were applied to the cohort during specimen collection.

113 Through data supplied by the Public Health Agency Northern Ireland, we estimate that only a small 114 proportion of samples may have been derived from previously HPV vaccinated women (5.9\%), thus 115 the majority of samples included in this study are from HPV unvaccinated women. Following routine 116 examination of the biopsy in each reporting laboratory, consultant pathologists selected the most 117 appropriate FFPE block containing the highest grade of disease reported. The selected cervical 118 tissue blocks were sent to the Department of Cellular \& Molecular Pathology, Northern Health \& 119 Social Care Trust for HPV determination. For the purposes of the present study, analysis was restricted to samples identified as cervical intraepithelial neoplasia (CIN) grades I, II and III, SCC and AC. On reception of the FFPE tissue blocks, pathology records were accessed and clinical pathological information including patient age, sample type and histology, were extracted. A unique study number was then assigned to each case and the link to the original case broken, ensuring

124 confidentiality and complete anonymisation of the results. Ethical approval for the study was granted from the Office of Research Ethics Committees NI (ORECNI ref: 08/NIIR02/104).

\section{Specimen processing}

128 FFPE tissue blocks underwent tissue microtomy and were processed under molecular pathology 129 conditions, to reduce the risk of cross contamination. Tissue lysis was performed using the QIAGEN 130 ATL (EDTA and 10\% sodium dodecyl sulphate) buffer (P/N 19076, Qiagen, Crawly, West Sussex, UK), 
131 in the presence of $20 \mu \mathrm{l}$ of proteinase K (P/N 19131, Qiagen, Crawley, West Sussex, UK). The tissue

132 was incubated at $56^{\circ} \mathrm{C} \pm 2^{\circ} \mathrm{C}$ for 24 hours with occasional vortex mixing during this incubation

133 period. During post enzymatic incubation, the lysate was added to processing tubes and was

134 subjected to automated DNA extraction on the Roche COBAS $^{\circledR} 480 \mathrm{X}$ module as per manufactures

135 protocols. Extracted DNA was eluted into buffer $\mathrm{EB}$ and stored at $-20^{\circ} \mathrm{C}$ until amplification. Detection

136 of HPV genotypes were undertaken using a modified Roche Linear Array HPV genotyping test (LA

137 HPV GT P/N:04391853 190) and the Linear Array detection kit (LA DK P/N: 03378179 190, Roche

138 Molecular Systems, Inc. Branchburg, NJ, USA). The modification from manufactures protocol

139 consisted of the addition of a compound into the HPV MasterMix, to allow for compatibility with the

140 DNA extracted from the COBAS $^{\circledR} 480$ X module. Extracted DNA was quantified via NanoDrop

141 spectrophotometry with all samples standardised to a concentration of $24 \mathrm{ng} / \mathrm{ul}$; the optimum level

142 determined in-house to allow for successful HPV detection in the background of human DNA and

143 reduce the number of test failures due to an "overloaded" PCR reaction. Of note, the Roche linear

144 array uses multiple type (mixed) probes to detect DNA from HPV-52 which limits the assay's ability

145 to discriminate HPV-52 status in the presence of HPV 33, 35 and/or 58 infections. The HPV-52

146 genotype was thus derived as positive if co-infection of HPV 33,35 and 58 was not present in the

147 sample. Cervical SCC samples that tested HPV negative were revisited, DNA isolated and retested to

148 ensure the result. Samples were considered HPV negative only when a linear array negative result

149 was obtained and confirmed by repeat testing.

150

\section{Specimen Reporting}

152 The term HR-HPV is used to describe a number of HPV genotypes that have been shown to be 153 associated with an increased risk of cervical cancer and include: HPV-16, 18, 31, 33, 35, 39, 45, 51,

$15452,56,58,59$ (carcinogenic), 68 (probably carcinogenic) and 66 (possibly carcinogenic) based on the 155 World Health Organization (WHO) HPV categorizations [Cogliano et al, 2005]. The term 'low-risk 
HPV' covers all other HPV genotypes detected by the Roche HPV linear array genotyping test. All HPV types identified by the Roche linear array are shown in Table 3.

158

\section{Statistical analysis}

160 The overall prevalence, genotype and age-specific HPV prevalence among pre-malignant lesions (CIN

$161 \mathrm{I}-\mathrm{III}$ ) and cervical cancers (SSC and AC) were estimated for all samples. The frequency of those testing positive for HPV-16 and HPV-18 with or without other HR-HPV genotypes was investigated. Women within the study were stratified into five year age bands, this was further classified into three age

164 groups for the following reasons; under 25 years (outside the age range for the current NI Cervical

165 Screening Programme, but current at the time of our previous prevalence study in the screened 166 population); 25 to 34 years (reported to have a higher transient HPV infection risk with no significant 167 underlying disease [Khan et al, 2005]), over 35 years (this group of HR-HPV positive is said to have a 168 higher chance of significant pathological outcome [Khan et al, 2005]). STATA IC/11.2 (StataCorp, 169 College Station, TX, USA) was used for all analyses.

170

171

172

173

174

175

176

177

178

179 
183 In total, 2,303 samples were received between April 2011 and February 2013. Figure 1 is a flow 184 diagram providing justification for the selection of study samples. Exclusions included 58 samples that were not tested due to overrepresentation in the low-grade dyskaryosis groups, a further 200 were excluded at the post-analytical phase of the study due to insufficient tissue remaining for molecular analysis. 218 samples were also excluded as they were not SCC, AC or CIN I-III pathologies. A total of 1,827 eligible samples were included for analysis, the majority of which were acquired through large loop excisions of the transformation zone (64.8\%) or punch biopsies (34.2\%).

\section{Prevalence of HPV infection:}

192 In total, 1,243/1,827 samples (68.0\%) tested positive for HPV, with the majority $1,183 / 1,827$ (64.8\%) 193 having HR-HPV infection. A total of 584/1,827 (32.0\%) of samples were HPV negative, $37.4 \%$ were 194 positive for HPV-16 $(n=684)$ and $5.1 \%$ for HPV-18 DNA $(n=93)$. Figure 2 outlines the overall HPV 195 genotype profile among the cohort and HPV multiplicity. The five most common HPV genotypes detected across all cervical pathologies examined were HPV-16 ( $n=684)$, HPV-31 ( $n=150)$, HPV-52 ( $n=125)$, HPV-18 (n=93) and HPV-33 (n=91) (Figure 2).

\section{HPV type-specific prevalence:}

200 The majority of samples were from CIN III cases (42.6\%). HPV DNA was detected in 262/545 (48.1\%) 201 of CINI samples, $280 / 425$ (65.9\%) of CIN II lesions, 633/779 (81.3\%) of CIN III specimens, 59/64 202 (92.2\%) of SCCs and 9/14 (64.3\%) of AC samples. Table 1 details the number of HPV genotypes 203 detected by pathological subtype. Half of all samples (49.7\%) had only one HPV genotype detected 204 ( $n=908$ ). Multiple HPV genotypes (>1) were more common in CIN I-III lesions than other cervical 205 pathologies. Among SCC specimens, 7.8\% had no HPV DNA detected and most (81.3\%) had only 1 206 HPV genotype persisting, Table 1. HPV-16 and/or HPV-18 DNA was present in the majority of SCC 207 (82.8\%) and AC (64.3\%) cases and over half (56.2\%) of CIN III samples, Table 2. Other HR HPV 
genotypes were more prevalent in CIN I-III pathologies, and present in less than $10 \%$ of SCCs and AC cases. LR-HPV genotypes were most common in lower grade cervical lesions and absent in cervical cancer specimens, Table 2 . Almost a third (32.0\%) of all pathologies were HPV negative. The distribution of HPV genotypes detected within each cervical pathology is detailed in Table 3. The current HPV vaccination genotypes (HR-HPV 16 and or HR-HPV 18) were found in at least $82.8 \%$ of ( $n=3 / 64)$ and HPV-52 ( $n=5 / 64)$ made up $96 \%$ of the HPV positive samples. HPV-16 was the most common HPV detected across all cervical pathologies, except for AC where HPV-18 predominated with HPV-16, HPV-51 and HPV-54 making up the remaining HPV genotypes present, Table 3.

\section{Age-specific prevalence for HPV infection:}

219 The pathological distribution of samples by five-year age group is shown in Table 4. The mean age of 220 women included in the study was 32 years (range 16-93 years, standard deviation (SD) 9.4 years) and significantly differed between histopathological groups $(P<0.001)$. In total, 375 samples were from women aged 24 years and under, 887 from women aged 25 to 34 years and 565 samples from those aged 35 years and over. CIN I was more common in younger women and CIN II and CIN III most common in those aged 25-29 years. SCC was most common in women aged 35-39 years, Table 4.

226 The number of HPV genotypes decreased with increasing age, with just over half $(51.0 \%)$ of all HPV 227 infections found in tissue from women aged between 25-29 years, Table 1. Most tissue samples had 228 a single HPV genotype and this was more common in those aged over 60 years. Five or more HPV 229 genotypes were detected in some women but this was largely limited to those aged under the age of 23040 years, Table 1. $41.7 \%$ of women with cervical pathology had HPV-16 or HPV-18 detected, and the 231 highest proportion HPV 16/18 positive were over the age of 65 years, Table 2. Other HR-HPV 232 genotypes were more common in younger women, particularly those aged 35-39 years. LR-HPV 
233 genotypes were most common in those aged 55-59 years, with women over the age of 60 years 234 having no LR-HPV genotypes detected, Table 2.

235

236

237

238

239

240

241

242

243

244

245

246

247

248

249

250

251

252

253

254

255

256

257

258 
260 This is the largest population-based study investigating the HPV genotype distribution in women 261 with CIN I-III and cervical SCC and AC in NI. The overall prevalence of any HPV in SCC samples was 92.2\% and was $68.0 \%$ across all cervical samples investigated. HR-HPV was detected in $64.8 \%$ of all samples with HPV-16 being the most common HPV genotype identified, which is consistent with that described elsewhere in CIN cases across Europe in countries such as Spain, France and Germany [García-Espinosa et al, 2012; Monsonego et al, 2012; de Jonge et al, 2013; Leinonen et al, 2013; Rössler et al, 2013] and in invasive disease internationally [Bosch et al, 2008; de Sanjose et al, 2010; Li et al, 2011]. As previously reported the prevalence of HPV increased through CIN I-III lesions in NI [Anderson et al, 2013] from $48.1 \%$ in CIN I to $81.3 \%$ in CIN III cases. Most HPV positive samples had HR-HPV genotypes with HPV-16 and/or HPV-18 present in $20.6 \%, 35.3 \%$ and $56.2 \%$ of CIN I-III cases respectively.

In an examination of FFPE tissue from more than 6,000 women from 17 European countries using the SPF10-LiPA25 assay, including data from neighbouring Scotland, Ireland and Wales, Tjalma et al found HPV-16 was the most frequent HPV type detected in both CIN and invasive cervical cancer [Tjalma et al, 2013]. HPV-16 and/ or HPV-18 prevalence (among HPV positive cases) was reported as 45.8\% in CIN II and 67.3\% in CIN III cases [Tjalma et al, 2013], slightly higher than the current study. The authors reported HPV-31, 33, 35, 51, 52, 58 and 68 as the most frequently detected genotypes in women with high-grade CIN lesions. Apart from HPV-16, we similarly found that HPV-18, 31, 33, 45, 51 and 52 were the most common genotypes identified in high grade lesions. Building on previous meta-analyses of type-specific HPV prevalence worldwide by specific grades of cervical disease [Clifford et al, 2003, 2005; Smith et al, 2007; Li et al, 2011] Guan et al in a further metaanalysis of 423 studies (144 of which were from Europe) using PCR assays based on various primers among cell or biopsy/tissue cervical diagnoses also showed an increasing HPV prevalence with increasing severity of cervical disease, with HPV-16 the most frequently detected HR-HPV type in all 
grades [Guan et al, 2012]. The prevalence (including HPV negative cases in the denominator) of HPV16 was $27.6 \%, 39.8 \%$ and $58.2 \%$ and HPV-18 prevalence $9.0 \%, 10.0 \%$ and $7.4 \%$ in $\mathrm{CIN}$ I to CIN III cases respectively [Guan et al, 2012], again higher than the estimates reported in the present study, variation which may have arisen from methodological differences in HPV detection techniques. The majority of SCCs (92.2\%) in the present study were HPV positive, this is in accordance with the proportions of invasive cervical cancers (the majority of which were SCCs) testing HPV positive in other countries of the UK [Mesher et al, 2014], Sweden, Spain Italy and eastern Europe [Du et al, 2011; Alemany et al, 2012; Giorgi Rossi et al, 2012; Guan et al, 2012; Piana et al, 2013; Pista et al, 2013; Škamperle et al, 2013; Tjalma et al, 2013; Kjær et al, 2014; Simanaviciene et al, 2014].

There were only 14 cases of AC included in the current investigation, and therefore our study is likely underpowered to investigate HPV prevalence in this subgroup. Of note however, HPV-18 was the most common HPV type in AC cases with a prevalence of $42.9 \%$ in the current study, akin to a recent Scottish estimate of $44.0 \%$ (among HPV positive cases) [Powell et al, 2013] which examined HPV DNA in FFPE tissue detected using the SPF10-DEIA/LiPA25-PCR assay. The prevalence of HPV-16 and/or HPV-18 was 64.3\%, lower than reported in an English multi-site investigation of HPV DNA in cervical cytology and cervical cancer biopsies using the Roche Linear array typing system (81.9\%, among HPV positive cases) [Howell-Jones et al, 2010] and among AC cases from other European studies (94.6\%) [Tjalma et al, 2013]; perhaps due to a lower HPV-18 rate.

The number of HPV genotypes detected in the current study varied across pathological grade, with 306 the lowest percentage of single genotypes (31.0\%) in CIN I lesions and the highest proportion 307 (81.3\%) in cervical SCCs, indicative that a single HPV genotype remains persistent in patients that 308 progress. Although HPV persistence has been shown to vary by geographical region, HPV-16, 18, 31, $30933,45,52$ and 58 are the most persistent HPV genotypes reported among women with invasive cervical cancer [Bernard et al, 2013; Rositch et al, 2013]. The most frequent single genotypes in the 
311 current investigation in SCCs were HPV 16, 18, 45, 31, 39 and HPV 52. Notably, this profile includes

312 several HPV genotypes which are not currently incorporated in the present HPV vaccine programme.

313 These should be considered in the next generation of anti-HPV vaccines. In line with the UK HPV 314 vaccination programme, in September $2012 \mathrm{NI}$ began using the quadrivalent vaccine Gardasil ${ }^{\circledR}$ 315 (Gardasil, Sanofi Pasteur MSD), with a relatively high uptake of $86.8 \%$ for all three doses in girls aged 316 12-13 years [HSC Public Health Agency Northern Ireland, 2014]. Markov modelling has shown that 317 the UK HPV vaccination programme would require $80 \%$ uptake to have a reduction of $66 \%$ in the 318 prevalence of high-grade precancerous lesions and a 76\% reduction in cervical cancer deaths [Kohli 319 et al, 2007]. Therefore the HPV genotypes covered by the current HPV vaccination programme will 320 lower the prevalence of HPV 16/18, as has already been evidenced in Scotland [Kavanagh et al, 321 2014], and should prevent the majority of cervical cancers in NI. The formerly used bivalent vaccine 322 (Cervarix ${ }^{\circledR}$ ) offers some cross-protection for HPV genotypes of the A7 species including HR HPV-31, 32333 and 45 [Paavonen et al, 2009; Malagón et al, 2012; De Vincenzo et al, 2013; Verdenius et al, 324 2013]. The potential effects of vaccine cross protection against other oncogenic non-target 325 genotypes should also be considered when conducting future cost-benefit analyses.

327 The principal strength of this study is its size and population-based design. The study was able to report the identification of high and low-risk HPV genotypes as well as the prevalence of multiple HPV infections. When comparing the HPV prevalence between countries it is important to consider that variations in HPV positivity may be explained by differences in the quality and type of samples analyzed (biopsies, surgical specimens or fresh tissue), as well as the methods of HPV detection and assessment.

334 While it is frequently reported that $99.7 \%$ of cervical SCCs are HPV positive [Walboomers et al, 335 1999], women have been shown to have cervical disease without testing HPV positive using current 336 methods. In a pooled analysis of 3 large Italian case series using three different PCR methods, 24 
337 (4.2\%) of 574 invasive cervical cancers were found to be 'true' HPV negative cases [Giorgi Rossi et al, 338 2012]. Similarly, Tjalma et al in large-scale data from 17 European countries found that $8.2 \%$ of 339 invasive cervical cancers were HPV negative [Tjalma et al, 2013]. HPV-negative carcinoma, if it exists 340 at all, is likely to be rare. In the present study $10 / 78$ invasive cervical cancers (12.8\%) tested HPV 341 negative. Although other aetiologic factors, such as mutations within the p53 gene, may explain 342 some HPV negative cases [Fogel et al, 1995] the potential for false negative results arising from 343 differences in analytic sensitivity for different HPV types particularly in the presence of multiple 344 infections, low titer or copy number of HPV DNA and inadequacy of the specimen should be 345 carefully considered. For instance, HPV genotyping analysis in the present study was undertaken 346 using the Roche linear array detection kit. Importantly, this assay uses PGMY L1 consensus primers 347 to amplify a 450-bp fragment. As it is well known that formaldehyde fixation provides low yields of 348 extractable DNA due to protein cross-linking and strand cleavage, such a large amplicon size 349 provides the potential for false negative results on FFPE tissue. Whilst the detection of HPV in fresh 350 frozen tissue appears superior [Odida et al, 2010], this would have been difficult to acquire and process in a large population-based study such as this.

In conclusion, HPV-16 was identified as the main HPV genotype associated with cervical disease in

$354 \mathrm{NI}$, contributing to around $83.0 \%$ of the cervical SCCs investigated. Provided there is sustained high HPV vaccine coverage in $\mathrm{NI}$, the current HPV vaccination programme should prevent the majority of cervical cancers but coverage of other HR-HPV genotypes with high prevalence and oncogenic potential including HPV-31, 39, 45 and 52 and the potential influence of cross protection, should be considered in any future polyvalent vaccines.

\section{AKNOWLEDGEMENTS:}

361 This project was funded under the research and development office, Public Health Agency (PHA) for $362 \mathrm{NI}$; the NI Cancer Registry is also funded through the PHA. The authors would like to thank the other 
members of the Northern Ireland HPV working group for their contribution: Boyle, M (Department of Health, Social Services and Public Safety); Owen, T (Public Health Agency); Clarke, R. (Southern Health \& Social Care [HSC] Trust); McCluggage, G (Belfast HSC Trust); Coyle, P (Belfast HSC Trust); McCance, D (Queen's University Belfast); Cameron, I (Western HSC Trust) and McGibben, D (Belfast HSC Trust).

FIGURE LEGENDS:

Figure 1: Flowchart of sample selection and eligibility

Figure 2: Overall HPV genotype profile denoting the prevalence of single and multiple HPV infections

\section{REFERENCES:}

Alemany L, Pérez C, Tous S, Llombart-Bosch A, Lloveras B, Lerma E, Guarch R, Andújar M, Pelayo A, Alejo M, Ordi J, Klaustermeier J, Velasco J, Guimerà N, Clavero O, Castellsagué X, Quint W, Muñoz N, Bosch FX, de Sanjosé S (2012) Human papillomavirus genotype distribution in cervical cancer cases in Spain. Implications for prevention. Gynecol Oncol 124: 512-517 doi:10.1016/j.ygyno.2011.11.024. papillomavirus in adolescents: strategies to improve outcomes (CME multimedia activity). J Adolesc Health 50: IBC doi:10.1016/j.jadohealth.2011.10.014. Anderson L, O'Rorke M, Jamison J, Wilson R, Gavin A (2013) Prevalence of human papillomavirus in women attending cervical screening in the UK and Ireland: new data from northern Ireland and a systematic review and meta-analysis. J Med Virol 85: 295-308 doi:10.1002/jmv.23459. (2013) Comparing human papillomavirus prevalences in women with normal cytology or invasive cervical cancer to rank genotypes according to their oncogenic potential: a meta-analysis of observational studies. BMC Infect Dis 13: 373 doi:10.1186/1471-2334-13-373. Muñoz N (2008) Epidemiology and natural history of human papillomavirus infections and typespecific implications in cervical neoplasia. Vaccine 26 Suppl 1: K1-K16 doi:10.1016/j.vaccine.2008.05.064.

393 papillomavirus prevalence in 5 continents: meta-analysis of 1 million women with normal cytological 394 findings. J Infect Dis 202: 1789-1799 doi:10.1086/657321.

395 Cancer Research UK (2014) Cervical cancer http://www.cancerresearchuk.org/cancer396 info/cancerstats/types/cervix.

397 Castellsagué X (2008) Natural history and epidemiology of HPV infection and cervical cancer. Gynecol 
399 Clifford GM, Rana RK, Franceschi S, Smith JS, Gough G, Pimenta JM (2005) Human papillomavirus 400 genotype distribution in low-grade cervical lesions: comparison by geographic region and with 401 cervical cancer. Cancer Epidemiol Biomarkers Prev 14: 1157-1164 doi:10.1158/1055-9965.EPI-044020812.

403 Clifford GM, Smith JS, Plummer M, Muñoz N, Franceschi S (2003) Human papillomavirus types in 404 invasive cervical cancer worldwide: a meta-analysis. Br J Cancer 88: 63-73 405 doi:10.1038/sj.bjc.6600688.

406 Cogliano V, Baan R, Straif K, Grosse Y, Secretan B, Ghissassi F El (2005) Carcinogenicity of human 407 papillomaviruses. Lancet Oncol 6: 204 doi:10.1016/S1470-2045(05)70086-3.

408 Du J, Näsman A, Carlson JW, Ramqvist T, Dalianis T (2011) Prevalence of human papillomavirus (HPV) 409 types in cervical cancer 2003-2008 in Stockholm, Sweden, before public HPV vaccination. Acta Oncol 410 50: 1215-1219 doi:10.3109/0284186X.2011.584556.

411 Fogel S, Ahomadegbe J, Lebihan M, Barrois M, Riou G (1995) Characterization of a new p53-mutated 412 and hpv-negative human squamous-cell cervical carcinoma-derived cell-line. Int J Oncol 6: 681-686.

413 García-Espinosa B, Moro-Rodríguez E, Alvarez-Fernández E (2012) Genotype distribution of human 414 papillomavirus (HPV) in histological sections of cervical intraepithelial neoplasia and invasive cervical 415 carcinoma in Madrid, Spain. BMC Cancer 12: 533 doi:10.1186/1471-2407-12-533.

416 Giorgi Rossi P, Sideri M, Carozzi FM, Vocaturo A, Buonaguro FM, Tornesello ML, Burroni E, Mariani L, 417 Boveri S, Zaffina LM, Chini F (2012) HPV type distribution in invasive cervical cancers in Italy: pooled 418 analysis of three large studies. Infect Agent Cancer 7: 26 doi:10.1186/1750-9378-7-26.

419 Guan P, Howell-Jones R, Li N, Bruni L, de Sanjosé S, Franceschi S, Clifford GM (2012) Human 420 papillomavirus types in 115,789 HPV-positive women: a meta-analysis from cervical infection to 421 cancer. Int J Cancer 131: 2349-2359 doi:10.1002/ijc.27485.

422 Howell-Jones R, Bailey A, Beddows S, Sargent A, de Silva N, Wilson G, Anton J, Nichols T, Soldan K, 423 Kitchener $\mathrm{H}$ (2010) Multi-site study of HPV type-specific prevalence in women with cervical cancer, 424 intraepithelial neoplasia and normal cytology, in England. Br J Cancer 103: 209-216 425 doi:10.1038/sj.bjc.6605747.

426 HSC Public Health Agency Northern Ireland (2014) Annual HPV vaccine coverage in Northern Ireland: 427 2012-13 http://www.publichealthagency.org/sites/default/files/directorates/files/2012-2013.pdf 428 (accessed: 20/11/2014).

429 IARC Working Group on the Evaluation of Carcinogenic Risks to Humans. (2012) A Review of Human 430 Carcinogens. vol 100B. Biological Agents (Lyon).

431 Jaisamrarn U, Castellsagué X, Garland SM, Naud P, Palmroth J, Del Rosario-Raymundo MR, Wheeler 432 CM, Salmerón J, Chow S-N, Apter D, Teixeira JC, Skinner SR, Hedrick J, Szarewski A, Romanowski B, 433 Aoki FY, Schwarz TF, Poppe WAJ, Bosch FX, de Carvalho NS, Germar MJ, Peters K, Paavonen J, 434 Bozonnat M-C, Descamps D, Struyf F, Dubin GO, Rosillon D, Baril L (2013) Natural history of 435 progression of HPV infection to cervical lesion or clearance: analysis of the control arm of the large, 
randomised PATRICIA study. PLoS One 8: e79260 doi:10.1371/journal.pone.0079260.

437 de Jonge $M$, Busecke $G$, Heinecke A, Bettendorf O (2013) Human papillomavirus genotype 438 distribution in cytologically screened women from northwest Germany. Acta Cytol 57: 591-598 439 doi:10.1159/000355099.

440 Kavanagh K, Pollock KGJ, Potts A, Love J, Cuschieri K, Cubie H, Robertson C, Donaghy M (2014) 441 Introduction and sustained high coverage of the HPV bivalent vaccine leads to a reduction in 442 prevalence of HPV 16/18 and closely related HPV types. Br J Cancer 110: 2804-2811 443 doi:10.1038/bjc.2014.198.

444 Khan MJ, Castle PE, Lorincz AT, Wacholder S, Sherman M, Scott DR, Rush BB, Glass AG, Schiffman M 445 (2005) The elevated 10-year risk of cervical precancer and cancer in women with human 446 papillomavirus (HPV) type 16 or 18 and the possible utility of type-specific HPV testing in clinical 447 practice. J Nat/ Cancer Inst 97: 1072-1079 doi:10.1093/jnci/dji187.

448 Kjær SK, Munk C, Junge J, Iftner T (2014) Carcinogenic HPV prevalence and age-specific type 449 distribution in 40,382 women with normal cervical cytology, ASCUS/LSIL, HSIL, or cervical cancer: 450 what is the potential for prevention? Cancer Causes Control 25: 179-189 doi:10.1007/s10552-013451 0320-z.

452 Kohli M, Ferko N, Martin A, Franco EL, Jenkins D, Gallivan S, Sherlaw-Johnson C, Drummond M 453 (2007) Estimating the long-term impact of a prophylactic human papillomavirus 16/18 vaccine on 454 the burden of cervical cancer in the UK. Br J Cancer 96: 143-150 doi:10.1038/sj.bjc.6603501.

455 Leinonen MK, Anttila A, Malila N, Dillner J, Forslund O, Nieminen P (2013) Type- and age-specific 456 distribution of human papillomavirus in women attending cervical cancer screening in Finland. $\mathrm{Br} J$ 457 Cancer 109: 2941-2950 doi:10.1038/bjc.2013.647.

458 Li N, Franceschi S, Howell-Jones R, Snijders PJF, Clifford GM (2011) Human papillomavirus type 459 distribution in 30,848 invasive cervical cancers worldwide: Variation by geographical region, 460 histological type and year of publication. Int J Cancer 128: 927-935 doi:10.1002/ijc.25396.

461 Louvanto K, Rintala MA, Syrjänen KJ, Grénman SE, Syrjänen SM (2010) Genotype-specific persistence 462 of genital human papillomavirus (HPV) infections in women followed for 6 years in the Finnish Family 463 HPV Study. J Infect Dis 202: 436-444 doi:10.1086/653826.

464 Malagón T, Drolet M, Boily M-C, Franco EL, Jit M, Brisson J, Brisson M (2012) Cross-protective 465 efficacy of two human papillomavirus vaccines: a systematic review and meta-analysis. Lancet Infect 466 Dis 12: 781-789 doi:10.1016/S1473-3099(12)70187-1.

467 Mesher D, Cuschieri K, Hibbitts S, Jamison J, Sargent A, Pollock KG, Powell N, Wilson R, McCall F, 468 Fiander A, Soldan K (2014) Type-specific HPV prevalence in invasive cervical cancer in the UK prior to 469 national HPV immunisation programme: baseline for monitoring the effects of immunisation. $J$ Clin 470 Pathol jclinpath - 2014-202681 - doi:10.1136/jclinpath-2014-202681.

471 Monsonego J, Zerat L, Syrjänen K, Zerat J-C, Smith JS, Halfon P (2012) Prevalence of type-specific 472 human papillomavirus infection among women in France: Implications for screening, vaccination, 473 and a future generation of multivalent HPV vaccines. Vaccine 30: 5215-5221 
475 Odida M, de Sanjose S, Sandin S, Quiros B, Alemany L, Lloveras B, Quint W, Kleter B, Alejo M, van 476 Doorn L-J, Weiderpass E (2010) Comparison of human papillomavirus detection between freshly 477 frozen tissue and paraffin embedded tissue of invasive cervical cancer. Infect Agent Cancer 5: 15 478 doi:10.1186/1750-9378-5-15.

479 Paavonen J, Naud P, Salmerón J, Wheeler CM, Chow S-N, Apter D, Kitchener H, Castellsague X, 480 Teixeira JC, Skinner SR, Hedrick J, Jaisamrarn U, Limson G, Garland S, Szarewski A, Romanowski B, 481 Aoki FY, Schwarz TF, Poppe WAJ, Bosch FX, Jenkins D, Hardt K, Zahaf T, Descamps D, Struyf F, 482 Lehtinen M, Dubin G (2009) Efficacy of human papillomavirus (HPV)-16/18 AS04-adjuvanted vaccine 483 against cervical infection and precancer caused by oncogenic HPV types (PATRICIA): final analysis of 484 a double-blind, randomised study in young women. Lancet 374: 301-314 doi:10.1016/S0140485 6736(09)61248-4.

486 Piana A, Sotgiu G, Cocuzza C, Musumeci R, Marras V, Pischedda S, Deidda S, Muresu E, Castiglia P 487 (2013) High HPV-51 prevalence in invasive cervical cancers: results of a pre-immunization survey in 488 North Sardinia, Italy. PLoS One 8: e63395 doi:10.1371/journal.pone.0063395.

489 Pista A, de Oliveira CF, Lopes C, Cunha MJ (2013) Human papillomavirus type distribution in cervical 490 intraepithelial neoplasia grade 2/3 and cervical cancer in Portugal: a CLEOPATRE II Study. Int J 491 Gynecol Cancer 23: 500-506 doi:10.1097/IGC.0b013e318280f26e.

492 Powell N, Cuschieri K, Cubie H, Hibbitts S, Rosillon D, De Souza SC, Molijn A, Quint W, Holl K, Fiander 493 A (2013) Cervical cancers associated with human papillomavirus types 16, 18 and 45 are diagnosed 494 in younger women than cancers associated with other types: a cross-sectional observational study in 495 Wales and Scotland (UK). J Clin Virol 58: 571-574 doi:10.1016/j.jcv.2013.08.020.

496 Rositch AF, Koshiol J, Hudgens MG, Razzaghi H, Backes DM, Pimenta JM, Franco EL, Poole C, Smith JS 497 (2013) Patterns of persistent genital human papillomavirus infection among women worldwide: a 498 literature review and meta-analysis. Int J Cancer 133: 1271-1285 doi:10.1002/ijc.27828.

499 Rössler L, Reich O, Horvat R, de Souza SC, Holl K, Joura EA (2013) Human papillomavirus in high500 grade cervical lesions: Austrian data of a European multicentre study. Wien Klin Wochenschr 125: 501 591-599 doi:10.1007/s00508-013-0403-6.

502 de Sanjosé S, Diaz M, Castellsagué X, Clifford G, Bruni L, Muñoz N, Bosch FX (2007) Worldwide 503 prevalence and genotype distribution of cervical human papillomavirus DNA in women with normal 504 cytology: a meta-analysis. Lancet Infect Dis 7: 453-459 doi:10.1016/S1473-3099(07)70158-5.

505 de Sanjose S, Quint WG, Alemany L, Geraets DT, Klaustermeier JE, Lloveras B, Tous S, Felix A, Bravo 506 LE, Shin H-R, Vallejos CS, de Ruiz PA, Lima MA, Guimera N, Clavero O, Alejo M, Llombart-Bosch A, 507 Cheng-Yang C, Tatti SA, Kasamatsu E, Iljazovic E, Odida M, Prado R, Seoud M, Grce M, Usubutun A, 508 Jain A, Suarez GAH, Lombardi LE, Banjo A, Menéndez C, Domingo EJ, Velasco J, Nessa A, Chichareon 509 SCB, Qiao YL, Lerma E, Garland SM, Sasagawa T, Ferrera A, Hammouda D, Mariani L, Pelayo A, 510 Steiner I, Oliva E, Meijer CJ, Al-Jassar WF, Cruz E, Wright TC, Puras A, Llave CL, Tzardi M, Agorastos T, 511 Garcia-Barriola V, Clavel C, Ordi J, Andújar M, Castellsagué X, Sánchez GI, Nowakowski AM, Bornstein 512 J, Muñoz N, Bosch FX (2010) Human papillomavirus genotype attribution in invasive cervical cancer: 
513 a retrospective cross-sectional worldwide study. Lancet Oncol 11: 1048-1056 doi:10.1016/S1470-

514 2045(10)70230-8.

515 Simanaviciene V, Gudleviciene Z, Popendikyte V, Dekaminaviciute D, Stumbryte A, Rubinaite V, 516 Zvirbliene A (2014) Studies on the prevalence of oncogenic HPV types among Lithuanian women 517 with cervical pathology. J Med Virol doi:10.1002/jmv.24073.

518 Škamperle M, Kocjan BJ, Maver PJ, Seme K, Poljak M (2013) Human papillomavirus (HPV) prevalence 519 and HPV type distribution in cervical, vulvar, and anal cancers in central and eastern Europe. Acta 520 dermatovenerologica Alpina, Pannonica, Adriat 22: 1-5.

521 Smith JS, Lindsay L, Hoots B, Keys J, Franceschi S, Winer R, Clifford GM (2007) Human papillomavirus 522 type distribution in invasive cervical cancer and high-grade cervical lesions: a meta-analysis update.

523 Int J Cancer 121: 621-632 doi:10.1002/ijc.22527.

524 Smith JS, Melendy A, Rana RK, Pimenta JM (2008) Age-specific prevalence of infection with human

525 papillomavirus in females: a global review. J Adolesc Health 43: S5-S25, S25.e1-e41

526 doi:10.1016/j.jadohealth.2008.07.009.

527 Tjalma WA, Fiander A, Reich O, Powell N, Nowakowski AM, Kirschner B, Koiss R, O'Leary J, Joura EA,

528 Rosenlund M, Colau B, Schledermann D, Kukk K, Damaskou V, Repanti M, Vladareanu R, Kolomiets L,

529 Savicheva A, Shipitsyna E, Ordi J, Molijn A, Quint W, Raillard A, Rosillon D, De Souza SC, Jenkins D,

530 Holl K (2013) Differences in human papillomavirus type distribution in high-grade cervical

531 intraepithelial neoplasia and invasive cervical cancer in Europe. Int J Cancer 132: 854-867

532 doi:10.1002/ijc.27713.

533 Trottier H, Mahmud SM, Lindsay L, Jenkins D, Quint W, Wieting SL, Schuind A, Franco EL (2009)

534 Persistence of an incident human papillomavirus infection and timing of cervical lesions in previously

535 unexposed young women. Cancer Epidemiol Biomarkers Prev 18: 854-862 doi:10.1158/1055-

536 9965.EPI-08-1012.

537 Verdenius I, Groner JA, Harper DM (2013) Cross protection against HPV might prevent type

538 replacement. Lancet Infect Dis 13: 195 doi:10.1016/S1473-3099(13)70024-0.

539 De Vincenzo R, Ricci C, Conte C, Scambia G (2013) HPV vaccine cross-protection: Highlights on

540 additional clinical benefit. Gynecol Oncol 130: 642-651 doi:10.1016/j.ygyno.2013.05.033.

541 Vink MA, Bogaards JA, van Kemenade FJ, de Melker HE, Meijer CJLM, Berkhof J (2013) Clinical

542 progression of high-grade cervical intraepithelial neoplasia: estimating the time to preclinical cervical

543 cancer from doubly censored national registry data. Am J Epidemiol 178: 1161-1169

544 doi:10.1093/aje/kwt077.

545 Walboomers JM, Jacobs M V, Manos MM, Bosch FX, Kummer JA, Shah K V, Snijders PJ, Peto J, Meijer

546 CJ, Muñoz N (1999) Human papillomavirus is a necessary cause of invasive cervical cancer

547 worldwide. J Pathol 189 : 9-12.

548 Wentzensen N, Walker J, Schiffman M, Yang HP, Zuna RE, Dunn ST, Allen RA, Zhang R, Sherman M, 549 Gold MA, Wang SS (2013) Heterogeneity of high-grade cervical intraepithelial neoplasia related to 550 HPV16: implications for natural history and management. Int J Cancer 132: 148-154 
551 doi:10.1002/ijc.27577.

552 WHO/ICO Information Centre on HPV and Cervical Cancer (2010) Human Papillomavirus and related 553 cancers in the United Kingdom, summary report.

554 
Table 1: Percentage distribution of the number of HPV genotypes detected by pathological subtype and 5-year age group.

\begin{tabular}{|c|c|c|c|c|c|c|c|}
\hline \multicolumn{8}{|c|}{ Number of HPV Genotypes detected (\% of each pathology) } \\
\hline Pathology & HPV negative & 1 & 2 & 3 & 4 & 5 or more & Total n (\%) \\
\hline CIN I & $283(51.9)$ & $169(31.0)$ & $63(11.6)$ & $19(3.5)$ & $9(1.7)$ & $2(0.4)$ & $545(100.0)$ \\
\hline CIN II & $145(34.1)$ & $217(51.1)$ & $46(10.8)$ & $15(3.5)$ & $1(0.2)$ & $1(0.2)$ & $425(100.0)$ \\
\hline CIN III & $146(18.7)$ & $462(59.3)$ & $129(16.6)$ & $32(4.1)$ & $4(0.5)$ & $6(0.8)$ & $779(100.0)$ \\
\hline SCC & $5(7.8)$ & $52(81.3)$ & $6(9.4)$ & $1(1.6)$ & $0(0.0)$ & $0(0.0)$ & $64(100.0)$ \\
\hline AC & $5(35.7)$ & $8(57.1)$ & $0(0.0)$ & $1(7.1)$ & $0(0.0)$ & $0(0.0)$ & $14(100.0)$ \\
\hline Age group (yrs) & HPV negative & 1 & 2 & 3 & 4 & 5 or more & Total n (\%) \\
\hline Under 25 & $115(30.7)$ & $172(45.9)$ & $64(17.1)$ & $18(4.8)$ & $3(0.8)$ & $3(0.8)$ & $375(100.0)$ \\
\hline $25-29$ & $152(28.7)$ & $270(51.0)$ & 79 (14.9) & $21(4.0)$ & $6(1.1)$ & $1(0.2)$ & $529(100.0)$ \\
\hline $30-34$ & $110(30.7)$ & $186(52.0)$ & $44(12.3)$ & $14(3.9)$ & $1(0.3)$ & $3(0.8)$ & $358(100.0)$ \\
\hline $35-39$ & $74(33.3)$ & $119(53.6)$ & $23(10.4)$ & $4(1.8)$ & $1(0.5)$ & $1(0.5)$ & $222(100.0)$ \\
\hline $40-44$ & $51(33.8)$ & $77(51.0)$ & $16(10.6)$ & $6(4.0)$ & $1(0.7)$ & $0(0.0)$ & $151(100.0)$ \\
\hline $45-49$ & $41(44.6)$ & $39(42.4)$ & $9(9.8)$ & $2(2.2)$ & $1(1.1)$ & $0(0.0)$ & $92(100.0)$ \\
\hline $50-54$ & $24(49.0)$ & $17(34.7)$ & $6(12.2)$ & $1(2.0)$ & $1(2.0)$ & $0(0.0)$ & $49(100.0)$ \\
\hline $55-59$ & $10(35.7)$ & $13(46.4)$ & $3(10.7)$ & $1(3.6)$ & $0(0.0)$ & $1(3.6)$ & $28(100.0)$ \\
\hline $60-64$ & $3(33.3)$ & $6(66.7)$ & $0(0.0)$ & $0(0.0)$ & $0(0.0)$ & $0(0.0)$ & $9(100.0)$ \\
\hline $65+$ & $4(28.6)$ & $9(64.3)$ & $0(0.0)$ & $1(7.1)$ & $0(0.0)$ & $0(0.0)$ & $14(100.0)$ \\
\hline TOTAL & $584(32.0)$ & 908 (49.7) & $244(13.4)$ & $68(3.7)$ & $14(0.8)$ & $9(0.5)$ & $1,827(100.0)$ \\
\hline
\end{tabular}


Table 2: Type of HPV genotypes detected by cervical pathology and 5-year age group.

\begin{tabular}{|c|c|c|c|c|c|}
\hline Pathology & $\begin{array}{c}\text { HPV-16 } \\
\text { and or } \\
\text { HPV-18 } \\
\text { n (\%) }\end{array}$ & $\begin{array}{l}\text { Other High-risk HPV } \\
\text { genotypes* }\end{array}$ & $\begin{array}{c}\text { Low risk HPV } \\
\text { genotypes } \\
\text { Only } \\
\text { n (\%) }\end{array}$ & HPV negative & n (\%) \\
\hline CIN I & $112(20.6)$ & $121(22.2)$ & $29(5.3)$ & $283(51.9)$ & $545(100.0)$ \\
\hline CIN II & $150(35.3)$ & $110(25.9)$ & $20(4.7)$ & $145(34.1)$ & 425 (100.0) \\
\hline CIN III & $438(56.2)$ & $184(23.6)$ & $11(1.4)$ & $146(18.7)$ & $779(100.0)$ \\
\hline SCC & 53 (82.8) & $6(9.4)$ & $0(0.0)$ & $5(7.8)$ & $64(100.0)$ \\
\hline AC & $9(64.3)$ & $1(7.1)$ & $0(0.0)$ & $5(35.7)$ & $14(100.0)$ \\
\hline \multicolumn{6}{|l|}{ Age group (yrs) } \\
\hline Under 25 & $154(41.1)$ & $93(24.8)$ & $13(3.5)$ & $115(30.7)$ & $375(100.0)$ \\
\hline $25-29$ & $237(44.8)$ & $127(24.0)$ & $13(2.5)$ & $152(28.7)$ & $529(100.0)$ \\
\hline $30-34$ & $151(42.2)$ & $82(22.9)$ & $15(4.2)$ & $110(30.7)$ & $358(100.0)$ \\
\hline $35-39$ & $84(37.8)$ & $59(26.6)$ & $5(2.3)$ & $74(33.3)$ & $222(100.0)$ \\
\hline $40-44$ & $59(39.1)$ & $36(23.8)$ & $5(3.3)$ & $51(33.8)$ & $151(100.0)$ \\
\hline $45-49$ & $34(37.0)$ & $12(13.0)$ & $5(5.4)$ & $41(44.6)$ & $92(100.0)$ \\
\hline $50-54$ & $18(36.7)$ & $5(10.2)$ & $2(4.1)$ & $24(49.0)$ & 49 (100.0) \\
\hline $55-59$ & $12(42.9)$ & $4(14.3)$ & $2(7.1)$ & $10(35.7)$ & $28(100.0)$ \\
\hline $60-64$ & $4(44.4)$ & $2(22.2)$ & $0(0.0)$ & $3(33.3)$ & $9(100.0)$ \\
\hline $65+$ & $9(64.3)$ & $1(7.1)$ & $0(0.0)$ & $4(28.6)$ & $14(100.0)$ \\
\hline TOTAL n (\%) & $\begin{array}{c}762 \\
(41.7)\end{array}$ & $421(23.0)$ & $60(3.3)$ & $584(32.0)$ & $1,827(100.0)$ \\
\hline
\end{tabular}


Table 3: HPV genotype distribution by cervical pathology

Cervical histology

\begin{tabular}{|c|c|c|c|c|c|c|}
\hline HPV genotype & AC & CIN I & CIN II & CIN III & SCC & Total \\
\hline HPV 16 & 3 (21.4) & $87(16.0)$ & $136(32.0)$ & 407 (52.3) & 51 (79.7) & $684(37.4)$ \\
\hline HPV 31 & $0(0.0)$ & $35(6.4)$ & $29(6.8)$ & $84(10.8)$ & $2(3.1)$ & $150(8.2)$ \\
\hline HPV 52 & $0(0.0)$ & $22(4.0)$ & $33(7.8)$ & $65(8.3)$ & $5(7.8)$ & $125(6.8)$ \\
\hline HPV 18 & $6(42.9)$ & $29(5.1)$ & $17(4.0)$ & $39(5.0)$ & $3(4.7)$ & $93(5.1)$ \\
\hline HPV 33 & $0(0.0)$ & 18 (3.3) & $15(3.5)$ & $58(7.5)$ & $0(0.0)$ & $91(5.0)$ \\
\hline HPV 51 & $1(7.1)$ & $17(3.1)$ & $25(5.9)$ & $28(3.6)$ & $0(0.0)$ & 71 (3.9) \\
\hline HPV 45 & $0(0.0)$ & $14(2.6)$ & $10(2.4)$ & $31(4.0)$ & $3(4.7)$ & $58(3.2)$ \\
\hline HPV 39 & $0(0.0)$ & $20(3.7)$ & $12(2.8)$ & $14(1.8)$ & $1(1.6)$ & $47(2.6)$ \\
\hline HPV 58 & $0(0.0)$ & $11(2.0)$ & $13(3.1)$ & $17(2.2)$ & $0(0.0)$ & $41(2.2)$ \\
\hline HPV 66 & $0(0.0)$ & $22(4.0)$ & $6(1.4)$ & $10(1.3)$ & $0(0.0)$ & $38(2.1)$ \\
\hline HPV 35 & $0(0.0)$ & $9(1.7)$ & $12(2.8)$ & $16(2.1)$ & $0(0.0)$ & $37(2.0)$ \\
\hline HPV 59 & $0(0.0)$ & $14(2.6)$ & $8(1.9)$ & $8(1.0)$ & $0(0.0)$ & $30(1.6)$ \\
\hline HPV 56 & $0(0.0)$ & $18(3.3)$ & $3(0.7)$ & $5(0.6)$ & $0(0.0)$ & $26(1.4)$ \\
\hline HPV 6 & $0(0.0)$ & $7(1.3)$ & $9(2.1)$ & $9(1.2)$ & $0(0.0)$ & $25(1.4)$ \\
\hline HPV 73 & $0(0.0)$ & $9(1.7)$ & $6(1.4)$ & $8(1.0)$ & $0(0.0)$ & $23(1.3)$ \\
\hline HPV 53 & $0(0.0)$ & $9(1.7)$ & $5(1.2)$ & $5(0.6)$ & $0(0.0)$ & $19(1.0)$ \\
\hline HPV 70 & $0(0.0)$ & $4(0.7)$ & $4(0.9)$ & $9(1.2)$ & $0(0.0)$ & $17(0.9)$ \\
\hline HPV 42 & $0(0.0)$ & $9(1.7)$ & $2(0.5)$ & $3(0.4)$ & $0(0.0)$ & $14(0.8)$ \\
\hline HPV 61 & $0(0.0)$ & $6(1.1)$ & $1(0.2)$ & $7(0.9)$ & $0(0.0)$ & $14(0.8)$ \\
\hline HPV 54 & $1(7.1)$ & $2(0.4)$ & $3(0.7)$ & $5(0.8)$ & $0(0.0)$ & $12(0.7)$ \\
\hline HPV 11 & $0(0.0)$ & $5(0.9)$ & $2(0.5)$ & $4(0.5)$ & $0(0.0)$ & $11(0.6)$ \\
\hline HPV 68 & $0(0.0)$ & $4(0.7)$ & $5(1.2)$ & $2(0.3)$ & $0(0.0)$ & $11(0.6)$ \\
\hline HPV CP6108 & $0(0.0)$ & $4(0.7)$ & $0(0.0)$ & $6(0.8)$ & $0(0.0)$ & $10(0.6)$ \\
\hline HPV 82 & $0(0.0)$ & $1(0.2)$ & $0(0.0)$ & $8(1.0)$ & $0(0.0)$ & $9(0.5)$ \\
\hline HPV 62 & $0(0.0)$ & $2(0.4)$ & $1(0.2)$ & $4(0.5)$ & $0(0.0)$ & $7(0.4)$ \\
\hline HPV 84 & $0(0.0)$ & $3(0.6)$ & $2(0.5)$ & $2(0.3)$ & $0(0.0)$ & $7(0.4)$ \\
\hline HPV 81 & $0(0.0)$ & $6(1.1)$ & $0(0.0)$ & $1(0.1)$ & $0(0.0)$ & $7(0.4)$ \\
\hline HPV 69 & $0(0.0)$ & $2(0.4)$ & $1(0.2)$ & $2(0.3)$ & $0(0.0)$ & $5(0.3)$ \\
\hline HPV 55 & $0(0.0)$ & $3(0.6)$ & $1(0.2)$ & $0(0.0)$ & $0(0.0)$ & $4(0.2)$ \\
\hline HPV 83 & $0(0.0)$ & $2(0.4)$ & $1(0.2)$ & $1(0.1)$ & $0(0.0)$ & $4(0.2)$ \\
\hline HPV is39 & $0(0.0)$ & $0(0.0)$ & $2(0.5)$ & $1(0.1)$ & $0(0.0)$ & $3(0.2)$ \\
\hline HPV 67 & $0(0.0)$ & $3(0.6)$ & $0(0.0)$ & $0(0.0)$ & $0(0.0)$ & $3(0.2)$ \\
\hline HPV 40 & $0(0.0)$ & $1(0.2)$ & $0(0.0)$ & $1(0.1)$ & $0(0.0)$ & $2(0.11)$ \\
\hline HPV 26 & $0(0.0)$ & $1(0.2)$ & $0(0.0)$ & $1(0.1)$ & $0(0.0)$ & $2(0.1)$ \\
\hline HPV 64 & $0(0.0)$ & $1(0.2)$ & $0(0.0)$ & $0(0.0)$ & $0(0.0)$ & $1(0.1)$ \\
\hline HPV 72 & $0(0.0)$ & $0(0.0)$ & $0(0.0)$ & $0(0.0)$ & $0(0.0)$ & $0(0.0)$ \\
\hline HPV 71 & $0(0.0)$ & $0(0.0)$ & $0(0.0)$ & $0(0.0)$ & $0(0.0)$ & $0(0.0)$ \\
\hline TOTAL & $11(78.5)$ & $400(73.6)$ & 364 (85.6) & 861 (110.8) & 65 (101.6) & $1701(93.3)^{*}$ \\
\hline
\end{tabular}

$\mathrm{AC}=$ adenocarcinoma $\mathrm{CIN}=$ Cervical Intraepithelial Neoplasia (grades I-III), SCC = Squamous Cell Carcinoma

* This figure does not add up to 1,243 (i.e.: the number HPV positive) as several patients may have had multiple HPV genotypes on testing 
Table 4: Pathological distribution of cohort (numbers of cases) by five-year age group

\begin{tabular}{|c|c|c|c|c|c|c|c|c|c|c|c|c|}
\hline & $\begin{array}{c}\text { Mean age } \\
\text { years ( } \pm \text { SD; range) } \\
\end{array}$ & & & & & AGE (years) & & & & & & n (\%) \\
\hline PATHOLOGY n (\%) & & $<25$ & $25-29$ & $30-34$ & $35-39$ & $40-44$ & $45-49$ & $50-54$ & $55-59$ & $60-64$ & $65+$ & TOTAL \\
\hline CIN I & $32(10 ; 16-69)$ & $144(26.4)$ & $136(25.0)$ & $82(15.1)$ & $55(10.1)$ & $51(9.4)$ & $42(7.7)$ & $19(3.5)$ & $11(2.0)$ & $3(0.6)$ & $2(0.4)$ & $545(100.0)$ \\
\hline CIN II & $32(9 ; 18-80)$ & $83(19.5)$ & $120(28.2)$ & $92(21.7)$ & $51(12.0)$ & $40(9.4)$ & $17(4.0)$ & $11(2.6)$ & $6(1.4)$ & $1(0.2)$ & $4(0.9)$ & $425(100.0)$ \\
\hline CIN III & $31(8 ; 18-64)$ & $146(18.7)$ & $268(34.4)$ & 169 (21.7) & $94(12.1)$ & $53(6.8)$ & $27(3.5)$ & $12(1.5)$ & $7(0.9)$ & $3(0.4)$ & $0(0.0)$ & $779(100.0)$ \\
\hline$S S C$ & $43(14 ; 23-93)$ & $1(1.6)$ & $3(4.7)$ & $12(18.8)$ & $19(29.7)$ & 7 (10.9) & $5(7.8)$ & 7 (10.9) & $3(4.7)$ & $1(1.6)$ & $6(9.4)$ & $64(100.0)$ \\
\hline$A C$ & $42(16 ; 23-73)$ & $1(7.1)$ & $2(14.3)$ & $3(21.4)$ & $3(21.4)$ & $0(0.0)$ & $1(7.1)$ & $0(0.0)$ & $1(7.1)$ & $1(7.1)$ & $2(14.3)$ & $14(100.0)$ \\
\hline TOTAL n (\%) & & $375(20.5)$ & $529(28.9)$ & $358(19.6)$ & $222(12.2)$ & $151(8.3)$ & $92(5.0)$ & $49(2.7)$ & $28(1.5)$ & $9(0.5)$ & $14(0.8)$ & $1,827(100.0)$ \\
\hline
\end{tabular}




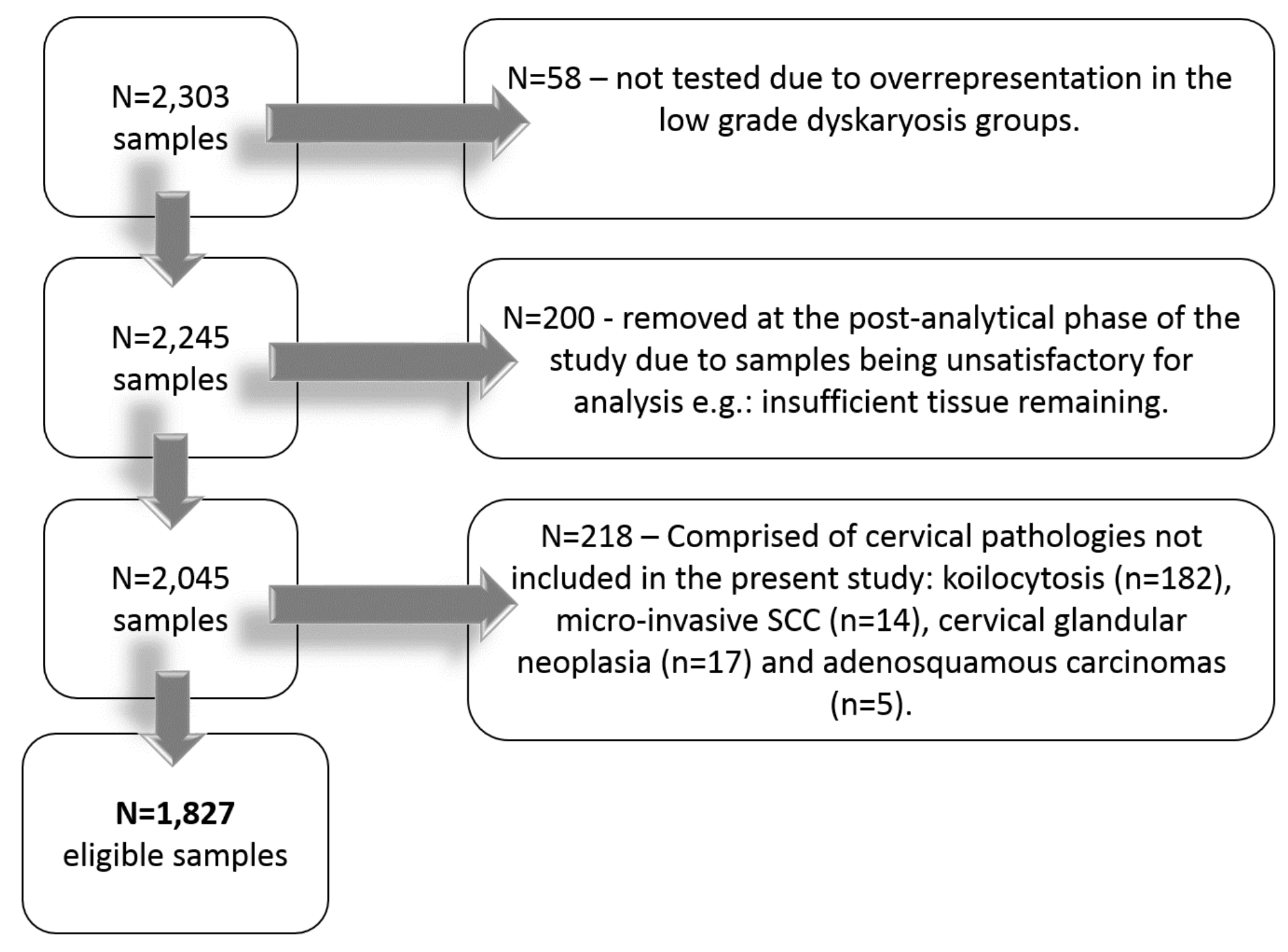




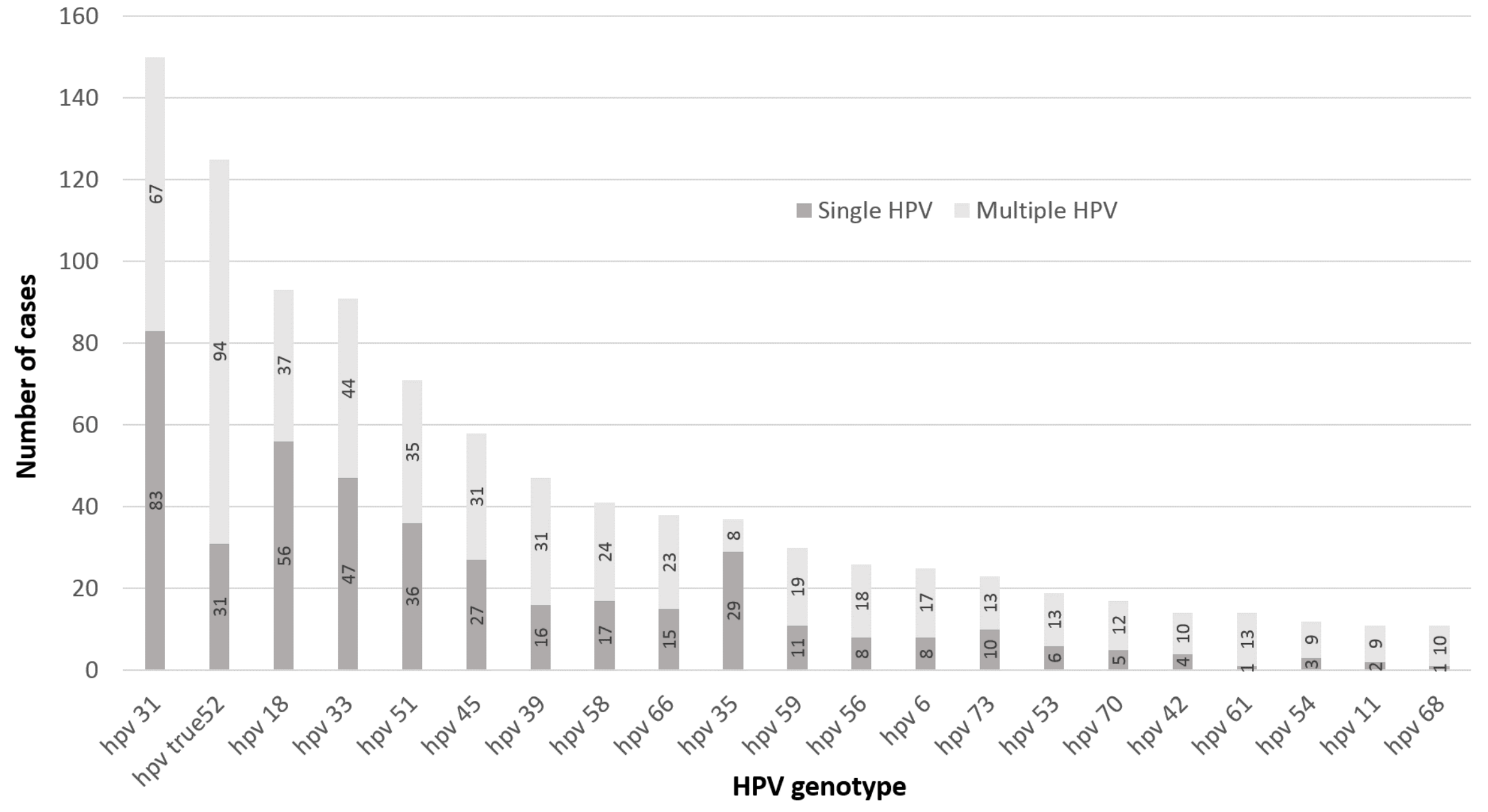

HPV genotypes omitted above (no. of single/multiple infections): HPV 16 (480/204), HPV CP6108 (1/9), HPV 82 (0,9), HPV 62 (0/7), HPV 84 (1/6), HPV 81 (3/4), HPV 69 (1/4), HPV 55 (0/4), HPV 83 (2/2), HPV IS39 (1/2), HPV 67 (2/1), HPV 40 (0/2), HPV $26(1 / 1), \operatorname{HPV} 64(0 / 1), \operatorname{HPV} 72(0 / 0), \operatorname{HPV} 71(0 / 0)$. 